\title{
O Sol, a Pele e os Protectores Solares
}

O bronzeamento da pele, tão em moda nos últimos anos, tem levado a inúmeros estudos sobre a acção dos raios solares sobre a pele. Os raios solares, se por um lado são benéficos (produção de vitamina D tão importante para o crescimento e formação óssea), têm também inúmeros inconvenientes como o envelhecimento prematuro da pele, alteração na pigmentação, fenómenos de fotosensibilização e até cancro cutâneo.

Para melhor compreendermos a acção das radiações solares, far-se-á uma breve revisão sobre a sua constituição e capacidade de penetração na pele.

No espaço, o sol emite um espectro contínuo que se estende das ondas rádio às ondas gama, representando a própria luz uma ínfima parte deste espectro electromagnético. A luz compõe-se de radiaçð̃es de infra-vermelho (IV), com um comprimento de onda $(\lambda)$ de 760-1400 $\mathrm{nm}$, de visível de $\lambda 760-400 \mathrm{~nm}$ de ultra-violeta (UV) de 400-200 nm.

Os raios infra-vermelhos e visíveis possuem fundamentalmente acção térmica pela sua degradação em calor, e os ultra-violetas com propriedades bioquímicas e excitomotoras são os raios responsáveis pela maior parte dos efeitos cutâneos nocivos provocados pelo sol. Os raios UV subdividem-se em 3 partes diferentes: UVA de $\lambda$ 320-400 nm, UVB de $\lambda$ 320-280 nm e UVC de $\lambda<280$ nm.

A radiação solar é modificada ao atravessar a atmosfera terrestre que constitui o nosso primeiro meio de protecção. A camada de ozono da atmosfera absorve quase completamente os UVC, e parcialmente os B, deixando passar os A na sua quase totalidade.

É necessário haver uma exposição ao sol muito controlada se não se quer correr o risco de efeitos secundários indesejáveis. Uma pele não bronzeada não deve receber na primeira vez uma exposição de mais de 15 minutos ao sol, indo aumentando esta sucessivamente. Os raios responsáveis por uma pigmentação retardada e duradoura são os UVB, enquanto os UVA produzem uma pigmentação imediata mas transitória. Esta aparece alguns minutos após a irradiação e mantém-se até ao fim do dia, desaparecendo rapidamente.

O poder penetrante das radiações depende do seu comprimento de onda, sendo a penetração da radiação cada vez mais profunda à medida que se avança do ultra-violeta para o infra-vermelho. As radiaçðes visível, IV e UVA atingem a derme, os UVB penetram na epiderme e os UVC ficam retidos na córnea.

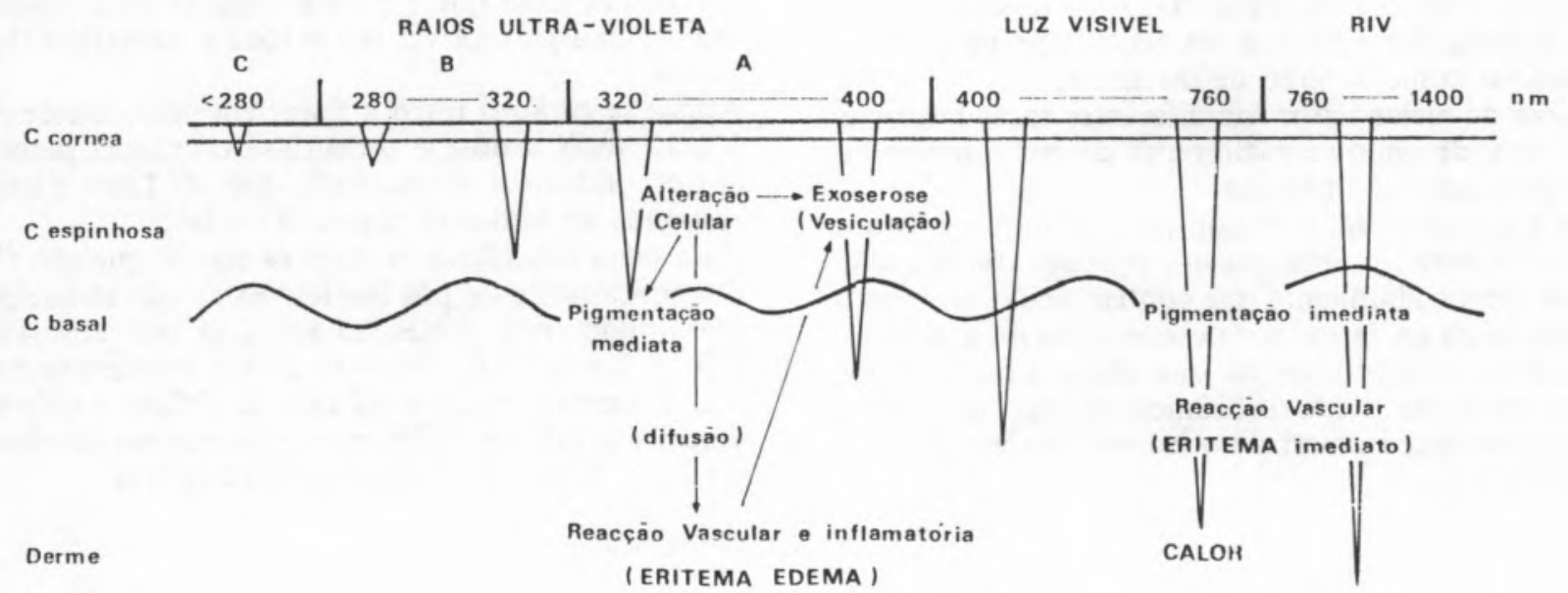

Acção das radiações solares na pele e seu grau de penetração segundo os comprimentos de onda

a Faculdade de Ciências de Lisboa. 
Por exposição ao sol, a pele defende-se, dispersando e reflectindo os raios luminosos; parte destes são absorvidos pelas proteínas das células epidérmicas e dérmicas, pelos ácidos nucleicos e pela melanina.

A exposição ao sol causa dois tipos de bronzeamento: um imediato e um tardio. O imediato é causado pela oxidação dos precursores da melanina enquanto o tardio resulta da actividade dos melanócitos, que depositam melanina. A melanina é um pigmento de cor castanho-escuro, sintetizado numa célula especial, o melanócito, que se encontra entre a camada basal da epiderme e a sua lâmina basal.

A sintese da melanina que ocorre no interior do melanócito inicia-se com a produção do aminoácido, fenilalanina (tirosina).

Simultaneamente é também sintetizada a tirosinase, enzima responsável pela oxidação da tirosina, a qual se transforma em 3,4-dihidroxifenilalanina (DOPA) e este em DOPA-quinona que após necessárias transformaçōes origina melanina.

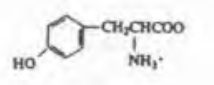

tirosina
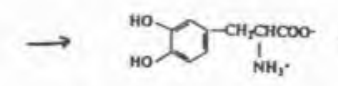

DOPA

DOPA-quinona

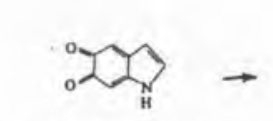

indol 5,6-quinona

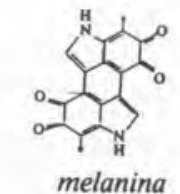

As vesículas cheias de tirosinase chamam-se pré-melanossomas e é nelas que se inicia a síntese de melanina. À medida que se acumula melanina nos pré-melanossomas, estes transformam-se em melanossomas onde existe melanina e actividade de tirosinase.

Terminada a síntese da melanina, o melanossoma enche-se de melanina e perde a sua actividade tirosinásica, recebendo o nome de grão de melanina.

O número de melanócitos nas diferentes raças humanas é o mesmo, devendo-se a diferença de cor à maior ou menor produção de melanina.

Contra a gressão solar o organismo possui mecanismos de defesa natural: o aquecimento provoca transpiração mais ou menos abundante que contém ácido urocânico (1) formado na epiderme por desaminação do aminoácido histidina, componente da queratina. Com efeito o isómero trans do ácido urocânico oferece uma certa protecção porque isomeriza ao isómero cis ao absorver radiação UVB.

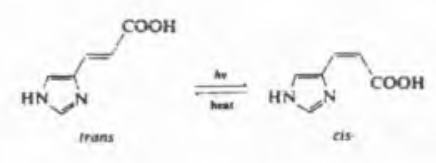

Depois de um banho de mar a pele está mais susceptivel a uma insolação, devido à eliminação do ácido urocânico.

Existe uma grande variedade de bronzeadores no comércio, não tendo muitos deles qualquer papel protector da pele. Os verdadeiros protectores solares devem conter um de dois tipos de produtos: os filtros, que absorvem parte da radiação, e os ecrans que a reflectem ou absorvem na sua quase totalidade.

Entre as substâncias componentes dos filtros contam-se o ácido p-aminobenzóico e seus ésteres, vários salicilatos entre eles o de fenilo, ésteres cinâmicos como o cinamato de benzilo e benzofenonas. Os veículos usados nos protectores solares podem também ter algum poder de absorção da radiação, tal como o de coco e de sésamo, que chegam a absorver $25 \%$ da radiação UV. Estes óleos têm ainda a vantagem de não serem tão facilmente eliminados após o banho de mar, mas têm o inconveniente, por serem pegajosos, de favorecerem a aderência da areia à pele.

Quanto às essências usualmente usadas nestes produtos de cosmética, há que ter o cuidado de evitar produtos com acção fotosensibilizante como por ex. a essência de bergamota que pode provocar uma reacção foto-tóxica de estimulação de melanogénese, podendo até haver destruição da célula e libertação da melanina na derme. Esta fotosensibilização pode ser responsável pelo aparecimento de diferenças de pigmentação que após o desaparecimento do bronzeado deixam aparecer zonas brancas e zonas hiperpigmentadas.

Após aplicação dum filtro sobre a pele, os UVs são absorvidos em grande parte pelo filtro que deixa passar apenas uma quantidade pequena de UVB e quase totalmente os UVA, situação que se passa com o vidro, que de facto actua como um filtro para a radiação UVB.

Os protectores solares que contêm filtros recebem índices numéricos de acordo com a protecção correspondente. $\mathrm{O}$ índice de proteç̧ão solar reflecte a exposição solar possível sem queimadura.

Para determinar o indice de protecção dum filtro utiliza-se um simulador solar que é uma lâmpada de xenon que emite praticamente as mesmas radiaçðes que o sol. Irradiam-se as costas de uma pessoa através de ocultador munido de 12 janelas de modo a administrar doses crescentes de radiação.

Vinte e quatro horas após irradiação, regista-se a dose eritemal mínima que é a mais pequena dose originando um eritema perceptível sobre toda a superfície de uma janela.

Aplica-se então o filtro a testar em doses crescentes de 1 a 12 vezes a dose e procura-se o eritema perceptível correspondente a determinada dose de filtro e isso corresponde ao índice de protecção solar.

Para além dos filtros existem os ecrans que são formados unicamente de pós inertes. Estes não são selectivos permitindo uma protecção total, já que absorvem os raios UVA e UVB. Entre os ecrans incluem-se componentes opacos como o dióxido de titânio e o óxido de zinco, e a pele protegida por estes compostos não sofre qualquer acção das radiaçð̃es ultra-violeta.

\section{Bibliografia}

- «Chemistry of Cosmetics", J. Chem. Ed., 802, 1978.

- J.A. Esteves, A.P. Baptista, F.G. Rodrigo, Dermatologia, Fund. C. Gulbenkian, Lisboa, 1980.

- M.S. Balsam et E. Sagarim ed., Cosmetics, Science and Technology, 2nd ed., vol. 3, 1974.

- Dermofarmácia e Cosmética, M.C. Costa, ed. Ass. Estudantes Fac. Farmácia de Lisboa, 1983.

- J. Coyle, R. Hill, D. Roberts ed., Light, Chemical change and life: a source book in photochemistry, The Open University, Milton Keynes, 1982.

- -A pele e o soln, folheto de apoio ao filme realizado por A. suime laboratório ROC, 1985. 